Cadernos de Filosofia Alemã 2, Р. 5-18, 1997

\title{
Leibniz: a afirmação da liberdade como determinação contingente
}

\author{
Tessa Lacerda*
}

\begin{abstract}
Resumo: O texto examina a aparente oposição entre a afirmação da liberdade humana, fundamentada no princípio da espontaneidade das substâncias, e a definição leibniziana de substância individual dada em termos lógicos, a saber, um sujeito cuja noção envolve, expressa ou virtualmente, todos os predicados.

Palavras-chave: substância individual - liberdade - contingência - necessidade
\end{abstract}

A possibilidade de classificar moralmente uma ação como boa ou má, justa ou injusta, assenta-se na pressuposição da liberdade dessa ação: é a liberdade que atribui ao agente a responsabilidade por sua ação e o constitui como sujeito moral. A afirmação da liberdade, por sua vez, fundamenta-se na idéia de contingência ou de possibilidade lógica de ocorrência, no futuro, de um fato e de seu contrário.

A capacidade divina de previsão dos futuros contingentes, graças à sua onisciência, não constitui propriamente um obstáculo à afirmação da liberdade, se distinguirmos presciência e determinação; daí Leibniz afirmar que "toda gente concordará estarem assegurados os futuros contingentes, visto Deus os prever, mas daqui não se segue a sua necessidade" (Leibniz 7, p. 86). Na filosofia leibniziana, no entanto, a previsão dos futuros contingentes está ligada à teoria da substância: a natureza de uma substância individual é definida, em termos lógicos, como um sujeito cuja noção envolve todos os predicados e cujo desenvolvimento apenas explicita essa série de predicados. Dessa forma, a noção de um ser deve conter, antes mesmo da Criação, toda a série de predicados pretéritos, presentes e futuros que pertencem a esse sujeito.

* Graduanda do Departamento de Filosofia - FFLCH-USP e bolsista FAPESP. 
Se a previsão dos futuros contingentes não os torna necessários, a causa da presciência (entendida com base na definição lógica de substância individual) parece deixar espaço apenas para um fatalismo absoluto nos eventos do mundo e para a perplexidade de um Arnauld ${ }^{1}$ (entre outros) ante o perigo iminente de negação do caráter moral das ações humanas. Este texto tem por objetivo caracterizar a aparente contradição entre liberdade e unidade substancial, a fim de apresentar, sumariamente, a solução leibniziana ao problema dos futuros contingentes (de importância capital para a constituição de uma Moral).

$$
* * *
$$

Leibniz inicia o oitavo parágrafo do seu Discurso de metafísica (1686), no qual se trata dos seres criados, com uma questão ${ }^{2}$ de difícil solução devido ao desacordo existente entre as filosofias da época. Deve-se admitir, como Malebranche e os partidários das causas ocasionais, que somente Deus é causa eficiente e que as criaturas constituem apenas ocasiões para a manifestação da causalidade divina? Ou deve-se reduzir o papel de Deus, tal como Descartes o faz, e afirmar que Ele assegura a mesma quantidade de movimento no mundo, mas que cabe aos seres criados modificar a direção desse movimento, imprimindo-lhe uma determinação particular?

Para Leibniz, ambas as teses, em certo sentido, podem ser admitidas, se forem corrigidos os erros que os filósofos misturaram a essas verdades. Na sua resposta à questão, Leibniz procura se guardar de dois excessos possíveis do cartesianismo, encontrando uma via intermediária entre o ocasionalismo e o materialismo, garantindo o papel das substâncias individuais na causalidade do mundo sem limitar a ação divina apenas à conservação da mesma quantidade de movimento no universo ${ }^{3}$. Concebe, então, uma causalidade segunda, eficiente, no plano das criaturas, ao lado da causalidade final do mundo, que só pode ser dada por Deus enquanto razão primeira e última de todas as coisas na medida em que é absoluta ou metafisicamente necessária.

Mais tarde ${ }^{4}$, em 1714, num pequeno ensaio intitulado Princípios da natureza e da graça fundados em razão, o filósofo será ainda mais categórico: inicia o texto afirmando que a substância é um ser capaz de ação. Ser e agir são sinônimos; não agir equivale a não existir.

A substância individual é dotada de uma total espontaneidade ou força ativa. A pretensão à existência de todos os seres enquanto meramente possíveis ${ }^{5}$ prefigura, antes mesmo da criação, essa força intrínseca da substância, a 
tendência para um fim. Assim, na criação, todos os seres recebem de Deus não somente a existência, mas uma certa atividade que garante a causalidade eficiente do mundo (interna a ele, diferentemente da concepção malebranchiana).

A reconstituição da noção escolástica de forma substancial permite a Leibniz conceber a força ativa como uma tendência intermediária entre a pura faculdade de agir e a ação mesma, ou entre a potência e o ato. A forma substancial leibniziana apresenta uma dupla particularidade ${ }^{6}$ : em primeiro lugar, corresponde a uma essência individual, isto é, a uma individualidade singular, única, e não, como para Santo Tomás, uma forma comum a muitos indivíduos. Para a tradição escolástica de inspiração aristotélico-tomista, os seres são compostos de matéria e forma; a forma determina a matéria, mas é a matéria que individualiza a forma, de modo a distinguir indivíduos de uma mesma espécie. Em segundo lugar, a forma substancial constitui uma força ativa; ela não é simplesmente o princípio ativo do composto substancial como potência nua, receptividade ou possibilidade de ação, mas um poder ou potência de passar de si mesma à ação e de produzir um efeito futuro por meio de um esforço. Essa potência de atuar é inerente a toda substância individual e dela resulta sempre uma ação; desse modo, as criaturas se vêem levadas por si mesmas a agir, sem requerer ajuda, mas apenas a supressão de obstáculos.

Todo ser criado tem um elemento de atividade que é marca de autonomia, ou seja, é capaz de passar de uma percepção a outra devido unicamente a um princípio interno (apetição). Tem também, no entanto, um elemento de passividade que é fonte de limitação. Se a substância se define como um ser capaz de ação, em que sentido podemos falar de passividade? Ora, as substâncias individuais são criadas por Deus de acordo com um determinado ponto de vista e, com base nessa perspectiva, refletem a totalidade do universo como um espelho, em virtude de uma espontaneidade que as faz encontrar em si mesmas traços de tudo que aí existe e acontece - passado, presente e futuro. Quando essa expressão se dá de forma distinta, a substância exerce sua potência ativa (passando a um grau mais alto de perfeição); porém, quando expressa algo confusamente, a saber, quando a razão do que acontece está em outra substância, sua potência é passiva ${ }^{7}$.

O que distingue os espíritos das outras substâncias individuais em relação à atividade e à passividade é que, neles, o elemento de limitação se encontra reduzido e a atividade se torna preponderante. Por essa dupla característica minimum de passividade e maximum de atividade - é que os espíritos podem ser considerados as criaturas mais perfeitas. 
O elemento ativo é preponderante nos espíritos porque eles são as únicas criaturas dotadas de razão, graças à qual os traços comuns a todas as substâncias, apetição e percepção, se encontram plenamente desenvolvidos ${ }^{8}$.

A razão possibilita o conhecimento das verdades necessárias e eternas; pelas suas abstrações o homem se eleva aos atos de reflexão que lhe permitem tomar consciência de si (le moi). Podemos, então, dizer que a reflexão, no plano do conhecimento, propicia a descoberta de verdades necessárias acerca de Deus e do universo; e, no plano da moralidade, é capaz de dotar os espíritos de qualidade moral, ou seja, essas almas guardam, além da identidade física e real de toda substância, uma identidade moral a fim de constituir uma pessoa.

Logo, os espíritos são as únicas substâncias que conhecem suas ações. Em outras palavras, a alma racional é capaz de deliberação (ou juízo), de encontrar a razão de sua ação (Dic cur hic) mediante o entendimento, e de ser levada a atuar por essa razão de acordo com sua vontade. Todas as suas ações supõem a sua vontade, depende do homem agir ou não em certas ocasiões depois de ter deliberado maduramente. É certo que nem sempre o espírito se serve desse poder, mas também é verdade que, dentre as criaturas, é a única que possui tal poder. Por isso, no espírito, a espontaneidade ou força ativa será entendida como liberdade.

As substâncias inteligentes, mais que espelhos vivos ou imagens do universo das criaturas, são imagens da Divindade; não apenas percebem as obras de Deus, mas capazes de conhecer o sistema do mundo criado, o imitam à medida de sua perfeição. A alma racional é arquitetônica nas ações voluntárias e, assim como a essência do homem exprime Deus logicamente, a sua existência deve exprimi-lo eticamente. Podemos dizer que, como pequenos deuses no seu domínio, os homens seguem leis particulares; sua vontade, como a do Criador, pode ser guiada pelo entendimento e dirigir-se sempre para o bem em geral ou o que lhe parecer melhor: por isso são livres.

$$
* * *
$$

As ações e paixões demandam uma unidade que as suporte, na qual subsistam e da qual resultem. Se ser e agir são sinônimos, ser e uno também serão. Assim, o que não é verdadeiramente um ser não é verdadeiramente um ser (cf. Leibniz, "Correspondance avec Arnauld", em Leibniz 6, p. 165). A substância individual pode ser entendida como a unidade de uma multiplicidade - de ações, paixões e atributos. 
A tese da uma unidade primordial da substância decorre da observação da correspondência entre a estrutura do real e as leis lógicas. Tal correspondência leva Leibniz a afirmar que a substância individual é constituída pelo sujeito lógico, e os atributos da substância, pelos predicados do sujeito. Essa definição lógica de substância leva em conta o caráter analítico da verdade e os princípios lógicos, ou seja, pressupõe que toda noção seja decomponível pela análise em elementos simples e, conseqüentemente, que toda proposição não faz mais que pôr em evidência a inclusão de um elemento (predicado) na noção considerada (sujeito).

A natureza de uma substância consiste precisamente nessa identidade entre sujeito e predicados; o primeiro termo contém os atributos, dando-lhes uma unidade, e mantém com eles uma relação intrínseca, devido à qual não se pode nem isolar os predicados nem o sujeito sem cair em mera abstração. Em outras palavras, a noção de cada ser criado contém expressa ou virtualmente toda a série de seus atributos ou fenômenos (passados, presentes e futuros). Mesmo um atributo que esteja incluído virtualmente na noção individual manifesta uma inerência do predicado ao sujeito; os acidentes não podem vir de fora para dentro de uma mônada ${ }^{9}$ (ou substância simples) - ela não tem portas nem janelas pelas quais qualquer coisa possa entrar ou sair (cf. Leibniz 4, p. 63). Dessa forma, pode-se conhecer de direito toda a série de fenômenos de um indivíduo, que só se desenvolve sensivelmente no tempo, de modo absolutamente a priori, como no caso das verdades necessárias, embora esse conhecimento só exista de fato para um entendimento infinito.

A atividade das substâncias consiste, então, numa causalidade eficiente que realiza espontaneamente um plano preconcebido. Do ponto de vista ético, as ações do sujeito devem aparecer ao longo da história como uma unidade primordial, como uma explicitação do que está contido em sua noção. Todo estado presente de uma substância é uma continuação de seu estado passado e está prenhe de futuro (cf. id., ibid., p. 65). Deste modo, a substância individual é princípio, origem e explicação de tudo que lhe acontece ao longo do tempo, e a lei de produção desses acontecimentos é apenas uma consequiência de sua espontaneidade fundamental, ou de sua liberdade (nos seres inteligentes).

Ora, mas em que sentido se pode falar de liberdade se os indivíduos se definem como tal em razão da série de seus predicados e se Deus conhece a noção completa de toda substância que, aos homens, só é dado conhecer no tempo? Não há livre escolha imprevisível para Deus. Portanto, se dentre as substâncias em geral considerarmos apenas a alma humana, o problema da iden- 
tidade entre o sujeito e seus predicados adquire uma importância particular, criando problemas, à primeira vista, insolúveis.

Leibniz parece descartar a hipótese de uma ligação extrínseca entre a substância e seus atributos, dependente de uma livre decisão divina. Em outras palavras, não acredita que Deus, ao criar o primeiro homem na série temporal, tenha ordenado tudo o que lhe aconteceria e à sua posteridade de modo que o conhecimento divino dos futuros contingentes derivasse dessa ordenação. $\mathrm{O}$ filósofo se aproxima mais da tese, em certo sentido, oposta a essa última, a saber: a ligação entre a substância e seus fenômenos é intrínseca e existe anteriormente aos decretos livres de Deus, escapando à vontade divina, e, por isso, o conhecimento da substância com todos os seus atributos pode ser obtido $a$ priori, do mesmo modo que se conhece as propriedades de uma figura geométrica $^{10}$.

Aceitando a segunda tese a conseqüência imediata é o aniquilamento da diferença entre verdades contingentes e verdades necessárias. Logo, é preciso aceitar que não existe uma separação de espécie entre predicados essenciais e acidentais; todos, sem exceção, são inerentes ao sujeito. Mas como conceber da mesma maneira um predicado como o pensamento para um espírito e o fato deste homem ser casado ou padre, médico ou teólogo? Como aceitar não haver diferença entre predicados que não podem se dar de outra forma sem contradição - como a morte para um ser criado - e predicados que podem diferir segundo as circunstâncias - como a data, o local e as condições da morte desse ser?

Aceitar que a ligação entre o indivíduo e seus atributos é intrínseca é negar a liberdade em proveito de um fatalismo absoluto nas ações humanas. Pode-se estabelecer uma distinção entre presciência e determinismo: com isso assegura-se que o conhecimento a priori ou a previsão dos futuros contingentes não os torna necessários. Como, no entanto, não aceitar como verdade que a causa da presciência parece implicar inevitavelmente um necessitarismo?

$$
* * *
$$

A fim de resolver esse paradoxo entre liberdade humana e presciência divina, ligado aos problemas postos por sua teoria da substância, Leibniz estabelecerá uma distinção entre certo e necessário. Considerará que existem duas espécies de consecução ou conexão entre o sujeito e os predicados de uma noção: uma necessária absolutamente, de modo que o contrário implica contradi- 
ção; outra necessária ex hypothesi, cujo contrário não implica absurdo lógico, mas moral. Tal distinção parece apontar para uma definição singular de liberdade.

É necessário o que ocorre de acordo com a primeira espécie de consecução. É certo e determinado, mas contingente, o que ocorre de acordo com a segunda - somente através dela é possível pensar as ações humanas como ações livres e, conseqüentemente, morais.

Ainda que a noção de substância individual encerre a priori todos os seus acontecimentos futuros, daí não decorre uma necessidade em sentido absoluto, i.e., é certo, mas não necessário, que tais acontecimentos, decorrendo dessa noção individual, se sucedam de acordo com ela. Tal certeza não pode ser considerada senão uma necessidade ex hypothesi ou de conveniência (relacionada às existências): é contingente em si mesma, pois não se fundamenta no Princípio de Contradição (o oposto, embora não aconteça, continua sendo possível). Baseia-se no livre arbítrio de Deus ou das criaturas, portanto nos decretos livres divinos, na sua vontade livre. Esses decretos inclinam a vontade humana, mas não tornam suas escolhas necessárias. O contingente, embora determinado, mantém-se distinto do necessário. A necessidade ex hypothesi é o grau ou o modo de necessidade próprio ao Princípio de Razão Suficiente - que afirma não poder algum fato ser tomado como verdadeiro ou existente, nem algum enunciado ser considerado verídico, sem que haja uma razão suficiente para ser assim e não de outro modo (cf. Leibniz 4, p. 66, entre outros textos) - na sua aplicação ao existente. A liberdade dos espíritos está livre da necessidade mas não de determinação, definindo-se, para Leibniz, como a possibilidade de realizar ou não uma ação de acordo com a vontade e segundo uma razão percebida pelo entendimento. Dessa forma, liberdade jamais poderá ser tomada como sinônimo de indiferença.

As escolhas que o homem faz ao longo do tempo (e que Deus pode conhecer de modo inteiramente a priori) atualizam virtualidades contidas na sua noção individual; assim, a razão que determina suas ações está dada por essa noção. Mesmo determinadas, tais ações permanecem livres porque pressupõem sempre uma escolha da vontade (logo, o homem não é determinado por uma razão a agir, ele se determina).

Dissemos que não há livre escolha imprevisível para Deus; para o homem, por outro lado, não há escolha previsível. A cada momento de sua existência, a criatura racional depara-se com um leque infinito de possibilidades de escolha. Diferentemente das verdades necessárias ou metafísicas que o homem pode deduzir de modo completo, no caso das verdades contingentes ele é inca- 
paz de fazer uma dedução completa ou, em outras palavras, é incapaz de conhecer todas as escolhas que fará ao longo da história - seria uma dedução infinita. A Lógica de Leibniz é infinitesimal, a doutrina do infinito vale para todos os seres. A natureza da substância é comparada aos números incomensuráveis. Se a noção de substância individual, como qualquer outra, é passível de análise, deve-se levar em conta que a análise possui graus, podendo ser mais ou menos completa. A substância não se desenvolve como uma série de teoremas, ela "não poderia desenvolver duma só vez todos os seus recônditos, pois estes vão até o infinito" (Leibniz 4, p. 69), só se esgotariam com uma série infinita.

O fundamento dessa explicação matemática da noção de substância se encontra na distinção, estabelecida por Leibniz, entre verdades necessárias e verdades contingentes. As verdades necessárias são aquelas cujo contrário não é possível, isto é, implica contradição. As verdades contingentes carecem dessa necessidade metafísica ou geométrica, seu oposto se mantém possível. Mas, também nesse caso, de acordo com a definição lógica de proposição verdadeira, a noção do predicado está contida na noção do sujeito de modo que a afirmação de uma verdade é sempre rigorosamente determinada e, conseqüentemente, inteligível a priori. A diferença é que uma afirmação necessária pode reduzirse, mediante a análise, à identidade, enquanto uma contingente não é passível de demonstração por esse meio. As verdades contingentes se relacionam com as necessárias, explica o autor (cf. Leibniz 8), assim como as razões dos números incomensuráveis se relacionam com as razões daqueles que são comensuráveis. De fato, é possível encontrar termos comuns nas noções de uma proposição necessária por meio da análise de suas definições, de modo semelhante ao que se passa na Matemática, quando se procura um fator comum entre um número menor e um maior, mostrando-se que o primeiro está contido no segundo. Ora, embora se saiba que um número maior contém outro incomensurável, é impossível encontrar um fator comum aos dois; do mesmo modo, ainda que se prossiga ao infinito a análise das noções presentes na afirmação de uma verdade contingente, jamais se encontra um termo comum a elas. A impossibilidade de se chegar a uma identidade quando se trata de verdades contingentes não se deve, portanto, a uma simples limitação do nosso entendimento, mas à natureza mesma desse objeto (cf. Belaval 2, p. 161).

As proposições sobre verdades contingentes se estendem à totalidade do mundo e, por isso, requerem, para que se esclareça a relação entre o sujeito e seus predicados, uma análise infinita que um entendimento finito é incapaz de realizar. Em outras palavras, diferentemente das proposições necessárias, que 
podem ser conhecidas pela simples análise de uma possibilidade lógica, as proposições contingentes, porque tratam das existências e supõem o Princípio de Razão Suficiente, só podem ser conhecidas pela análise integral do mundo real.

Um entendimento finito pode explicar as coisas do mundo encontrando a razão de um estado dado em um estado anterior a ele, mas, considerando que o curso da natureza é condicional, seria lançado em um progresso infinito. Explicando rigorosamente, a passagem de um ente contingente a outro ente igualmente contingente não pode ter fim - "em verdade, um ente contingente não é causa do outro, ainda que assim nos pareça" (Leibniz 8, p. 331). Uma verdade de fato é uma verdade que não comporta análise e não pode ser demonstrada em si mesma. Se para um entendimento infinito é possível compreender de que modo o predicado está inserido na noção do sujeito em uma proposição de fato, isso não significa que a análise tenha um termo. Não faz sentido falar em último termo de uma série infinita, "uma série infinita não tem, até mesmo para Deus, o termo último" (Belaval 1, p. 386). O contingente não se reduz ao necessário; por conta da infinidade, não é jamais inteiramente justificado. O entendimento divino é capaz de uma visão a priori de um número infinito de acontecimentos contingentes, por isso, valendo-se da noção singular de cada ser criado "Ele vê claramente a verdade de todos seus acidentes sem acudir a nada extrínseco, porque cada uma envolve a seu modo todas as outras e o universo inteiro" (Leibniz 8, p. 331). Para o homem, essa noção plena revela-se imperfeitamente na sucessão da experiência e no seio de uma infinidade de acontecimentos do mundo que a envolvem e a determinam ${ }^{11}$.

Em certa medida, poderíamos dizer que a ligação entre a substância e seus atributos é extrínseca já que pressupõe a infinidade do universo escolhido livremente por Deus. A substância, como uma noção individual e não relativa à espécie, envolve, no entanto, a totalidade das determinações que devem aparecer no curso de seu desenvolvimento por meio de uma conexão certa, fixada por Deus na criação. Rigorosamente, devemos afirmar que há uma ligação intrínseca, embora não necessária, entre o sujeito e seus predicados, de modo que a razão do segundo termo se encontra no primeiro, inclinando sem necessitar. Os predicados das substâncias singulares permanecem, para um entendimento finito, empíricos, mas, se de fato os julgamentos sobre as criaturas são empíricos, de direito estão contidos sempre na noção individual considerada. Se os homens fossem capazes de remontar aos primeiros possíveis, atributos de Deus, enxergariam as causas primeiras e a razão última de todas as coisas presentes na escolha primordial; entretanto, os desígnios divinos lhes são impenetráveis. 
A consideração do Princípio de Razão Suficiente torna possível admitir, ao lado da necessidade, a contingência; na determinação, a liberdade. Embora certas, as escolhas dos homens permanecem contingentes, não apresentando demonstrabilidade necessária - "a vontade se inclina sempre mais para o partido que ela toma, mas jamais está na necessidade de adotá-lo. É certo que ela seguirá esse caminho mas não é necessário que ela o siga" (Leibniz 10, § 43). Desse modo, a liberdade em Leibniz pode ser entendida em decorrência de sua definição de substância. A distinção entre verdades contingentes e necessárias explica por que o desenvolvimento dessa noção determinada é contingente (ou livre), i.e., certa, mas não necessária. Tudo que acontece à alma é consequiência de sua noção; ao escolher, o homem realiza (atualiza) sua noção individual. Em vez da contradição que, por um lado, a afirmação da liberdade, e, por outro, a afirmação da unidade primordial da substância (e, logo, da presciência divina), pareciam suscitar, percebe-se agora que uma é decorrência da outra.

$$
* * *
$$

A afirmação da liberdade repõe a moralidade. Sendo livres, os espíritos são capazes de entrar em sociedade com Deus num Reino Moral da Graça no Mundo Natural, sendo as únicas criaturas suscetíveis de castigo e recompensa. Dessa forma, o mundo não é apenas uma máquina sumamente admirável que manifesta a sabedoria e a potência do Arquiteto do universo, mas também a mais perfeita Cidade ou República em que se manifesta a bondade de seu Monarca.É o melhor dos mundos possíveis porque dotado não apenas de perfeição metafísica, mas também de perfeição moral.

\begin{abstract}
The text considers the so called opposition between the affirmation of the human freedom, based on the principle of the spontaneousness of the substances, and the leibnizian definition of individual substance given in logical terms, i.e., a subject whose notion comprehends all predicates in an explicit or implicit way.
\end{abstract}

Key-words: individual substance - freedom - necessity - contingency 


\section{Notas}

1. Cf. carta de 13 de março de 1686: "je trouve dans ces pensées tant de choses qui m'effraient, et que presque tous les hommes, si je ne me trompe, trouveront si choquantes, que je ne vois pas de quelle utilité pourrait être un écrit qui apparement sera rejeté de tout le monde" (Leibniz 9, p. 83).

2. O problema que Leibniz pretende enfrentar diz respeito ao estatuto ontológico das criaturas que constituem o universo. $O$ filósofo considera que a definição moderna de substância, i.e., de um ser que pode ser concebido por si e só depende de si mesmo para subsistir, corre o risco de fazer de Deus a única substância verdadeira levando a um panteísmo de tipo espinosano. A solução concebida por Leibniz é considerar um princípio de mudança interno às substâncias individuais.

3. Para Descartes, Deus conserva os estados sucessivos do mundo, que depende apenas do Criador, sem nada dever ao seu estado anterior; por isso, nada garante que o existente em determinado momento continuará existindo no momento subseqüente. Considerando a relação de Deus com as substâncias, ou seja, a manutenção, por parte d'Ele, do ser na existência, temos o caminho aberto para o ocasionalismo de Malebranche. Considerando, por outro lado, a relação das criaturas com os acidentes, podemos sustentar que Deus conserva apenas a força que deu às criaturas sem lhes dirigir, por meio da criação descontínua do mundo, de instante a instante, pela qual mantém a mesma quantidade de matéria e de deslocamento ou movimento. Daí o materialismo: Deus abandona a natureza a ela mesma, abandona, em última instância, a matéria à sua passividade. Para Leibniz, Deus não faz tudo; Ele não precisa estabelecer, a cada instante, os estados sucessivos do mundo; esses derivam-se uns dos outros graças a uma espontaneidade contínua da atividade própria das substâncias individuais. Mas o Criador não se limita a conservar a força que deu às criaturas; Ele prescreve uma direção para o desenvolvimento substancial (cf. Belaval 1, p. 437).

4. Em textos da maturidade do sistema leibniziano, como a Monadologia e os Princípios da natureza e da graça, a doutrina da substância precede a apresentação da doutrina de Deus, num movimento inverso ao plano clássico a que o Discurso de metafísica é fiel. Mediante um método que vai do simples ao complexo, da análise da substância à consideração de Deus e da cidade dos espíritos, Leibniz abandona o ritmo binário de descendência e ascendência (do exame de Deus ao exame das criaturas e dessas à união dos espíritos com Deus), para conceber a totalidade de seu sistema em função das substâncias, realizando uma tendência inicial própria de seu pensamento (cf. Le Roy, "Introduction", em Leibniz 9).

5. A diferença entre possíveis e existentes consiste em que os primeiros estão submetidos apenas à condição de harmonia interna enquanto os outros devem satisfazer a exi- 
gência de harmonia externa ou compossibilidade. Por isso, embora todos os possíveis tendam com igual direito à existência na medida de suas perfeições, somente alguns deles serão eleitos para realizar sua essência. Sua tendência à existência representa numa medida infinitamente pequena o desenvolvimento dessa essência, mas, deixados em si mesmos, os possíveis são incapazes de passar a um grau maior de desenvolvimento. Numa essência finita, diferentemente da essência infinita em que possibilidade e existência se confundem, a mera tendência não é suficiente para passar ao ato, uma vez que é contrariada por tendências análogas de outras essências em uma espécie de luta pela "sobrevivência" (para usar a analogia de E. Boutroux) na qual os demais possíveis representam um obstáculo ao seu desenvolvimento.

6. Cf. Le Roy, G. "Notes sur le Discours de Métaphysique et la Correpondance entre Leibniz et Arnauld", em Leibniz 6, p. 221.

7. Somente nesse sentido é concebível a mútua limitação das substâncias. Pode-se dizer que idealmente umas agem sobre as outras sendo obrigadas a se acomodar entre si, já que uma modificação pode aumentar a expressão de uma substância diminuindo a da outra, embora somente Deus atue realmente sobre elas. Vê-se, aqui, o primeiro traço do duplo caráter de Deus que toda substância traz consigo como a marca do obreiro na obra: a potência divina - toda substância estende seu poder às demais mantendo em sua dependência, embora idealmente, todos os seres do universo. O segundo traço é a sabedoria infinita do Criador refletida na expressão (e conhecimento, no caso das substâncias inteligentes), embora confusa, da totalidade do universo.

8. As enteléquias ou mônadas nuas dos corpos inorgânicos compostos caracterizam-se por um princípio de percepção e apetição; as almas irracionais, hierarquicamente acima delas mas abaixo dos espíritos, têm essas faculdades mais distintas em razão da memória que lhes oferece uma consecução à imitação da razão.

9. As mônadas são substâncias simples, isto é, sem partes, que agregadas a outras substâncias, constituem todas as coisas de que a natureza se compõe (cf. Leibniz 4, p. 63).

10. A analogia entre a noção individual de substância e a natureza do círculo é empregada por Leibniz, no parágrafo 13 do Discurso de Metafísica (bem como na Correspondência com Arnauld), para reafirmar a unidade primordial da substância já posta pelo parágrafo 8 do Discurso. Trata-se, no parágrafo 13, de explicitar a aparente contradição entre a definição lógica de substância individual e a afirmação da liberdade humana. Para tanto, a analogia tem o papel de ressaltar a identidade entre o sujeito e os predicados de uma noção individual, para explicar a possibilidade de conhecimento a priori dos futuros contingentes. Leibniz não explicita (como fará na Carta IX da Correspondência com Arnauld) mas pressupõe a diferença entre noções específicas (tal como a do círculo) e noções individuais (tal como a de Adão): uma noção específica é composta de um número finito de predicados e corresponde a uma verdade eterna, que é independente da vontade livre de Deus; uma noção individual designa um ser único e determinado de sua espécie, com- 
posto de uma infinidade de atributos, e corresponde a uma verdade de fato, i.e., supõe o decreto da vontade divina que decide livremente pela criação das existências. A analogia, empregada por Leibniz, identifica noções individuais e noções específicas (no que diz respeito à igualdade sujeito-predicados) sem estabelecer a distinção entre verdades necessárias e contingentes, por isso, a consequiência aparente imediata é a afirmação do fatalismo nas ações humanas.

11. Cf. Burgelin 3, p. 146; cf. também Leibniz 4, p. 66: "Há uma infinidade de figuras e movimentos presentes e passados entrando na causa eficiente deste meu ato presente de escrever, e uma infinidade de pequenas inclinações e disposições da minha alma presentes e passadas que entram na sua causa final."

\section{Referências bibliográficas}

1. BELAVAL, Y. Leibniz critique de Descartes. Paris, Gallimard, 1960.

2.___Leibniz, initiation à sa philosophie. Paris, Vrin, 1962.

3. BURGELIN, P. Commentaire du Discours de metaphysique de Leibniz. Paris, PUF, 1959.

4. LEIBNIZ, G. W. “A monadologia”. Em: Leibniz. São Paulo, Abril Cultural, 1973 (col. "Os Pensadores").

5. ___ . "Da origem primeira das coisas". Em: Leibniz. São Paulo, Abril Cultural, 1973 (col. "Os Pensadores”).

6.___ "Discours de métaphysique" et "Correspondance avec Arnauld". Introdução, texto e comentário de G. Le Roy. Paris, Vrin, 1984.

7. __ "Discurso de metafísica". Em: Leibniz. São Paulo, Abril Cultural, 1973 (col. "Os Pensadores").

8. _ "Verdades necessárias e contingentes". Em: Escritos filosóficos. E. de Olaso (org.). Buenos Aires, Charcas, 1982. 
9._._. Correspondance avec Arnauld. Paris, Vrin, 1966.

10. ___ Essais de théodicée sur la bonté de Dieu, la liberté de l'homme et l'origine du mal. Paris, Aubier, 1962.

11. La monadologie. Comentários de E. Boutroux. Paris, Delagrave, 1930.

12._. Nouveaux essais sur l'entendement humain. Paris, Flammarion, 1990. 